\title{
LA REBELIÓN DE LAS PALABRAS EN LA POESÍA DE RAFAEL BALLESTEROS
}

\section{Oscar BARRERO PÉREZ}

\section{Universidad Autónoma de Madrid}

La mayor dificultad que el lector de Rafael Ballesteros encuentra en el proceso de aproximación a sus versos es el hermetismo de unas referencias temáticas que tanto pueden tener de manifestación de un universo lírico intrasferible, como de expresión radical de un culturalismo exigente y sin concesiones. Pero no más fácilmente superables son los sucesivos, y numerosos, listones que el escritor malagueño instala en el recorrido por sus páginas, semejantes en todo momento a un campo de minas por donde asoman profusamente fragmentos lingüisticos a veces de acarreo, a veces de derribo de la propia construcción, ante los que en cualquier caso es obligado que el lector se detenga si su deseo es encontrar un significado inteligible a una literatura oscura y en muy buena medida indescifrable!

No se trata, sin embargo, de recuperar aquel experimentalismo que rejuveneció por unos afios un panorama que parecia dar la espalda al futuro a fuerza de tanto mirar hacia atrás con complacencia y, desde luego, sin ira. La impenetrabilidad de los textos que comento presenta unas caracteristicas distintas. En solo una de ellas deseo profundizar: lo que tienen de continuada vocación rupturista e innovadora en el plano meramente linguistico. Extender esta apreciación a otros territorios (el de la métrica, el de los contenidos de los poemas, el de las valoraciones estéticas...) será tarea propia de quienes adviertan o hayan advertido la posibilidad de aproximarse a ellos con la misma inquietud monográfica que me ha animado a acercarme al tema tan abstractivamente anunciado por mi título.

Mi primera preocupación es (caplatio benevolentiae más o menos de rigor) dejar sentada la dificultad de la empresa, incluso para quienes intentan (intentamos) desplazarnos por los dos espacios que se comunican en la palabra Filología: el literario y el linguístico (reitero, en cualquier caso, mi propósito de transitar ahora exclusivamente por este último). Una dificultad, dicho sea de paso, a la que no son ajenas las despreocupaciones editoriales que conducen inexorablemente a la errata. Despreocupaciones que no por sabidas, lamenta-

' El prólogo de José María Balcells a Poesta (1969-1989) (1995) es, en este sentido, un meritorio esfuezo de interpretación de la obra de Ballesteros. A los libros poéticos del volumen (Coniracifras [1969], Turpa ] 1972], Jacinta ]1983], La cava [1984] y Numeraria [1986]) ahado Testamenta, publicado en 1992. Abreviaré las referencias ( $C, T, J$, Cova, $N, T e s t)$, afladiendo en cada caso el dato imprescindible para identificar el poema de que se trate. 
das y padecidas en todas las cames deben obviarse, a manera de permanente recordatorio para quienes necesitan llamadas de atención que serfa deseable que algún dia fueran solo historia ${ }^{2}$.

Salvado ese obstácu lo no imputable al analista y sf a la desidia de que la Historia no consigue librar a España, el lector se tropieza con un nuevo problema, que no tendria necesidad de afrontar ante un autor más obediente a los moldes lingúisticos tradicionales: la aparición de palabras o expresiones que para unos merecerian el calificativo de heterodoxas y que fiscales más severos tildarán de errores ortográficos, ante los cuales es posible plantearse la existencia de una implacable errata, pero también la duda de si entra en juego la voluntad trasgresora del autor. Prescindo en el análisis, pues, de estos ejemplos inductores de la confusión ${ }^{3}$.

La subversión experimentalista procede por la vía destructiva (afirmación esta que, por supuesto, no implica que no haya una trascendencia en esa actuación radical). No renuncia a ella Ballesteros, pero es mucho mayor el núrnero de ejemplos que apelan a la construcción de una nueva lengua. En definitiva, esa ha sido la inquietud de todos aquellos que se han servido del neologismo para expresar ideas, sentimientos, vivencias cuyo traslado preciso no les parecia posible en la lengua estándar. De ahí surge una creación más o menos afortunada, más o menos original y más o menos necesaria.

${ }^{2}$ En mi trabajo me he impuesto ha supuesto la obtigación de consultar las primeras ediciones de los libros siempre que me ha sido posible. Ese cotejo me ha permitido corregir algunas observaciones iniciales, aunque no pocas dudas hayan quedado sin resolver.

${ }^{3}$ No obstante, relaciono a continuación los ejemplos claros de vulneración de las normas gramaticales (omito todas aquellas voces mal acentuadas): "robarle a los pies" $(C, 1)$, "de arriba a abajo" $(C, 7)$, "No hay derecho que" $(C, 9)$, "su por qué" $(C, 26)$, "primer peseta" $(C, 28)$, "avalanzaba " ( $T$, "Alimento a la mano...", "cs por cllo/eso que" (repetidas veces), buyes (Cava, "Sobre todo..."), explendentc $(J$, II), espúreo/as $(J$, IV; Test, "El pie"), explendian $(J, \mathrm{VI})$, explenden $(J, \mathrm{VII})$, zahíno por zaino $(J$, VIII, Test, "El pie"), exclusa $(J, X)$, hoquedades $(J, X I 1)$, "c hiede" $(J$, XII), enervaduras por nervaduras ( $N$, "Ocho"), "primer llamada" (Test, "Lo que nunca dije"), fragrante (Test, "El pie"), porqué como adverbio (Test, "El pantalón...", dos veces). No trato aqui vocablos como desapercibido ( $=$ inadvertido) o extroviente, ambos de reciente incorporación en el Diccionario Manual de la Real Academia. El registro de los neologismos que conforman este articulo no puede considerarse completo, pero si muy amplio: la exclusión de algunos vocablos que el lector de Ballesteros encuentre en sus libros y ro en mi trabajo puede deberse tanto al hecho de que dejo abierta la posibilidad de que se trate de una errata, como a mis dudas particulares sobre el significado de aquéllos. 
Las páginas del poeta andaluz se puebian de palabras inventadas, verbos con régimen inesperado, secuencias de vocablos yuxtapuestos, plurales anómaios, alteraciones en el orden normal de los elementos de la oración, palabras, frases y versos bruscamente interrumpidos, extraños cambios de género o de categoria gramatical, no pocos arcaísmos $y$ algún que otro americanismo ("contesta" como sustantivo $[J, \mathrm{Xlll}]$; "comprendés vos" $[J, \mathrm{XX}]$; las formas de presente "tiza" y "tizo", correspondientes a un verbo, "tizar", usado en Chile $[J$, V]), o vuigarismos ("cuála" $[J$, IX], "pilistra/s", forma popular de la planta llamada "aspidistra" [Test, "Los anillos de plata" y "El pantalón..."]). Todo un repertorio de violaciones de una noma que el escritor, con justificación o sin ella, parece considerar insuficiente para abarcar los límites de su Jiteratura.

No hablaré de neologismos de contenido (es decir, de significado o de sentido) en casi ningún caso, porque las peculiaridades del lenguaje poético permitirlan ampliar considerablemente los limites del concepto tal como aquí lo estoy entendiendo (piénsese, por ejemplo, en este sintagma: "Marco Tulio, el cicero" [Test, "El pie"], donde el nombre común, obviamente, no tiene nada que ver con la palabra usada por los profesionales de la imprenta; o en la incongruencia semántica de "A ambas las tres" [Test, "Mi pluma"]). Voy a centrarme, pues, casi de forma monográfica, en los neologismos de forma y, de alguna manera, en los de construcción.

La creación neojógica más frecuente en Rafael Ballesteros es aquella que parte de una raiz ya existente, a la que se añaden elementos nuevos que configuran una palabra posibjemente no utilizada por nadie hasta entonces ${ }^{4}$. Hay algún ejemplo, sin embargo, de asunción de innovaciones ajenas. La resonancia literaria, en estos poemas habitualmente oculta por una tupida cortina, se trasparenta con claridad en versos como el que contiene la palabra "muertamente" $(C, 22)$, que Ballesteros hereda de Aleixandre. $O$, de forma mucho más clara, en la imposible masculinización del conocido verso de Rubén Darío: "púber canéforo" (Test, "La esperma").

Salvo omisión por mi parte en el recuento, el citado líneas arriba es el único neologismo adverbial en este conjunto de obras. El resto de las categorias gramaticales suceptibles de experimentar variaciones lógicas de

Aunque reconozco las limitaciones de la metodologla, opto, para la consideración de una voz como neológica, por considerar su ausencia en las últimas ediciones de los diccionarios usual (1992) y Manual (\$989) de la Real Academia. Su inclusión en el repertorio que proporciono en estas páginas no presupone nada, claro está, sobre su hipotético empleo por otros escritores. Lógicamente, pars las palabras que ya han sido estudiadas en los fasclculos correspondientes del Diccionario Histórico de la Lengua Española editzdo por la Academia, ha sido imprescindible la consulta de esta obra en curso de publicación. He constatado, pues, la inexistencia en ella de testimorio alguno sobre palabras como afalladas, ambulear o amplura. 
alguna entidad (sustantivo, adjetivo y verbo) se ve afectado en proporciones relativamente similares. No se registra, pues, una tendencia clara en favor de la neologización de unos u otros elementos dependiendo de sus caracteristicas linguisticas.

Los ejemplos que enumero ahora, pertenecientes todos ellos a los tres bloques a que aludo, sirven como ilustración del propósito rupturista del poeta.

Sustantivos: "convensivan" ( $T$, "Turpa crece..."), "umbrera/s" ( $J$, II y XI), "otorgas" ( $J, V)$, "lazadura" $(J, V)$, "dicto" ( $J$, VII), "rohada" ( $J$, VII), "pitraca" ( $J$, VII), "procuro" ( $J$, VIII), "primura" ( $J$, IX), "drena" $(J$, IX), "boqueteria" $(J, \mathrm{X})$, "devoros" ( $J, \mathrm{XI})$, "engobe" ( $J, \mathrm{XII})$, "burbullo" $(J, \mathrm{XII})$, "enhebro" ( $J$, XIV), "doncelias" ( $J$, XIV), "querubi" ( $N$, "Cinco"; es palabra, sin embargo, no infrecuente en la lengua poética), "gima" (Test, "Antecedenta"), "gratln" (Test, "Mi cama"), "roa" (Test, "Mi cama"), "arego" (Test, "Mi cama"), "ululo" (Test, "El pie"), "arcales" (Test, "Lo negro..."), "argentas" (Test, "Los anillos de plata"), "contraformo" (Test, "Los anillos de plata"), "herrejada" (Test, "El pantalón..."), "guinardilla" (Test, "Los anillos de plata"), "lebrerio" (Test, "Mi tos"), "vienevén" (Test, "Mi tos"), "tíntinos" (Test, "Mi tos"), "embarramientos" (Test, "El pantalón..."), "latina" (Test, "El pantalón..."), "tedor" (Test, "La esperma"), "oferencia" (Test, "La esperma"), "galopino" (Test, "La esperma").

Adjetivos: "ayunosa" ( $J, \mathrm{I})$, "agallosos" ( $J$, II), "esmerosa" $(J$, III), "yedroso" ( $J$, III), "almenoso" ( $J$, III), "hondoso" $(J$, III), "hiperbolario" $(J$, VI), "terrisos" $(J, \mathrm{VI})$, "trivias" $(J, \mathrm{IX})$, "sienos" $(J, \mathrm{X})$, "aventinas" $(J, \mathrm{XII})$, "ubra" ( $J$, XIV), "osadiera" ( $J$, XV), "encinoso" (Test, "EI pie"), "inclinesca" (Tesl, "Lo que no fue..."), "sarméntico" (Test, "Lo que no fue..."), "córnicos" (Test, "Lo que no fue..."), "estradino" (Test, "Lo negro..."), "enarda" (Test, "Lo negro..."), "secundina" (Test, "Lo negro..."), "empezonado" (Test, "Mi pluma"), "motórica" (Test, "El pantalón..."), "tráctil" (Test, "El pantalón..."), "brámido" (Test, "El pantalón..."), "extéreas" (Test, "Los anillos de plata"), "grupales" (Test, "Los anillos de plata"), "afalladas" (Test, "Mi tos"), "hiáticas" (Test, "Mi tos"), "hóspita" (Test, "Mi tos"), "estrosa" (Test, "La esperma"), "alfanjina" (Test, "La esperma").

Verbos y participios: "ataconado" ( $C, 24)$, "boza" ( $T$, "Presentación del sexo"), "oqueadas" (Cava, "Antiguas pertenencias"), "fragiliza" (Cava, "La cava"), "parcian" ( $J, \mathrm{~V})$, "perpleja" como presente de indicativo $(J, \mathrm{~V})$, "orfebradas" ( $J$, VI), "flautaba" ( $J$, VIII), "respuesta" como 3." persona del singular $(J$, XIII), "exequian" ( $J$, XIII), "honde" ( $J$, "Dos"), "plintan" (Test, "Mi cama"), "desvastados" (Test, "Mi pluma"), "trasgando" (Test, "El pantalón..."), 
"plomizas" como 2." persona del singular (Test, "Mi tos"), "arquetipa" (Test, "El pantalón..."), "calderetea" (Test, "La esperma").

En la mayor parte de los vocablos enumerados en los tres bloques es posible percibir el cambio introducido por el autor sobre la base léxica ${ }^{3}$. En otros casos, sin embargo, la operación puede ser algo más compleja. Por ejemplo, "rilo" $(J, I)$, sustantivo anómalo formado sobre la base de "rilar" (= temblar); "volútil" $(J, \mathrm{IV})$, que deriva de "voluta"; "verberos" $(J$ XI), hipotético sustantivo evocador del verbo "verberar" (= azotar, especialmente haciéndolo el viento); o "sietuna", que se comprende al considerar su inserción precisamente en la séptima parte de Numeraria.

$Y$ es que frecuentemente el contexto es el que permite descifrar el significado del neologistno en cuestión. Entender que en el hecho de que un muchacho "no tieme sus pupilas" ( $J, V)$ tiene algo que ver la ternura no sería seguramente posible (al menos, no para el lector normal) si en los versos próximos no figurara por dos veces la palabra "terneza". Para revelar el significado del presente de indicativo "tenza" $(J, 1 \mathrm{X})$ hay que recurrir al verbo que lo acompaña en el siguiente verso ("canta"), lo que permite trasladarse al francés antiguo, en el que se designaba una composición poética provenzal con un vocablo que el español ha adaptado con la forma "tenzón".

Lógicamente, casi siempre el neologismo es flor de un verso, y no se repite en otro lugar. Pero no sucede asi con algunas palabras que reaparecen en el mismo poema, o en otro incluido en el libro que lo ha visto nacer, 0 , incluso, en una obra distinta. "Anginándome" $y$ "anginando" se leen en el poema 2 de Contracifras; "amadura" aparece en los dos primeros poemas de Jacinto; un imposible "branquiar" surge en dos libros distintos $(J, 11 ; N$, "Nueve"), y los adjetivos "incándido" (= incandescente) y "argenta" aparecen en más de un verso de Testamenta ("Mi cama" y "Los anillos de plata", y "Mi pluma" y "Los anillos de plata", respectivamente). Puede darse también la circunstancia de que una raiz determinada engendre palabras distintas, como sucede cuando se habla de "el labio llamarado" ( $T$, "Presentación del recuerdo") y de "el llamaral inmenso" $(J, \mathrm{~V})$.

Si en los casos hasta aqui enumerados puede pensarse, de una u otra forma, en la necesidad de ocupar con un nuevo elemento un espacio vacio, en los siguientes se registra la existencia de un sinónimo que, obviamente, el poeta no ha querido emplear, prefiriendo para su expresión crear ya que no ex nihilo, sí sobre bases distintas de las conocidas por la lengua estándar. Palabras

${ }^{3}$ Pero ni todas las palabras mencionadas tienen por qué ser neologismos en sentido estricto, ni para todas es posible encontrar un significado evidente. 
como "oposicionas" ( $C, 28)$, "tactar" ( $T$, "En una amanecida..."), "flamar" (Cava, "La sombra del estio"; J, XIV), "sanguinenta" (Cava, "Sobre todo..."), "periclar" ( $J$, II), "ambulea" ( $J$, III), "medrura" ( $J$, III), "reconcilia" $(J$, IV), "supleno" ( $J$, IV), "perpetuosas" ( $J$, VII), "alba" ( $J$, VIII), "enmuda" $(J$, IX), "tramados" $(J, X)$, "levitud" $(J, X)$, "ventillo" $(J, X)$, "chamusca" $(J, X)$, "torvera" $(J, \mathrm{XI})$, "engañura" $(J, \mathrm{XI})$, "amplura" $(J, \mathrm{XI})^{6}$, "recordario" $(J, \mathrm{XIV})$, "escopla" ( $N$, "Uno"), "continamiento" ( $N$, "Uno"), "palpear" ( $N$, "Cuatro"), "medito" ( $N$, "Cinco"), "glute" ( $N$, "Ocho"), "evaporecidos" (Test, "Antecedenta"), "incándido" (Test, "Mi cama", "Los anillos de plata"), "mendozas" (Test, "Mi cama"), "nuba" (Test, "Lo que nunca..."), "melancolioso" (Test, "Lo que nunca dije"), "ofusco" (Test, "Lo negro..."), "sangrosa" (Test, "Mi pluma"), maceterlo (Test, "Mi pluma"), "esquivano" (Test, "El pantalón..."), "salazo" (Test, "El pantalón...") "atemplan" (Test, "El pantalón..."), "templas" (Test, "La esperma"), "friegues" (Test, "La esperma"), tienen un correlato ortodoxo más o menos preciso pero al que, en cualquier caso, serla posible recurrir en el nivel del habla no poética: "opositas", "tocar", "flamear", "sanguinolenta", "periclitar", "ambular", "medrosla", "reconciliación", "suplico", "perpetuas", "albea", "enmudece", "entramados" / "tramas", "levedad", "vientecillo", "chamuscada", "torva", "engaf̃o", "amplitud", "recordatorio", "escoplea", "contención", "palpar", "meditación", "deglute", "evaporados", "incandescente", "mendocinas", "nubla", "melancólico", "ofuscado", "sangrante" / "sangriento" / "sanguinolento", "macetero", "esquivo", "salazón", "(a)temperan" / "templan", "templadas", "friegas".

Incluso los topónimos participan de esta radical renovación linguística propuesta por Ballesteros: "el sigüenza" ( $J$, VIII), "cimas y venecias" $(J, \mathrm{XV})$. También si debe inventarse un adjetivo procedente de un nombre o apellido, la opción elegida resulta ser poco acorde con lo esperado por el lector: de Pessoa, "pessosos" (Test, "Lo que nunca djje"), de Lampedusa, "lampedusco" y no "lampedusiano" (ibid.), o de Parménides "parménico" ( y no "parmenldeo"; Test, "El pantalón..."). Parece claro el propósito de construir entre esta poesia y su lector una pared que obligue a este a clevarse para poder contemplar lo que hay al otro lado de la lengua habitual en la comunicación.

Otra formula de extrañamiento utilizada en estos libros es el empleo de sufijos distintos de los posiblemente esperables: "rozante" donde quizá podríamos suponer "rozador" ( $T$, "Ataque al recuerdo"), "rielente" (¿"rielador"? [Cava, "En la mar..."]), "configurante" por e] más habitual

6 La documentación thás reciente de "amplura" en el Diccionario Histórico (fascículo 17." fechado en 1986) es nada menos que de 1422-337: Mosé Artagel Guadalfajara, Glosas Génesis. Desde entonces, no consta su empleo por ningún otro autor. 
"configurador" ( $N$, "Cinco"), "abandonante" (¿"abandonador"? [Test, "Mi pluma"I), "espejante" (esperariamos "espejeante" [Test, "Mi pluma"]), o "lomas jaenas" posiblemente por "lomas jaenesas", "jaeneras" o "jien(n)enses" (Test, "La esperma"). En algunos casos se procede por probable analogla con formas de alguna manera próximas, como cuando, seguramente evocando "verdoso", se lee "negroso" ( $J, 11)$. Un caso extremo es el de la palabra "coloraria", hipotética abstracción lingúística no por casualidad ideada en el seno del libro titulado Numeraria ("Nueve").

Ballesteros llega al punto de crear neologismos que son sinónimos entre si, radicalizando en su escritura las posibilidades de la variario estilistica. Asl, en la séptima parte de Jacinto leemos "mimosa" como tercera persona del singular de indicativo de un hipotético "mimosar", cuando algunas páginas atrás ha escrito "mimosea" ( $J$, II). Otro ejemplo: en el mismo poema, "zona arreducta" y "zona irreducta" $(J$, Il). Jugar con el lenguaje (ejercicio que tanto puede ser sano divertimiento como seria reflexión revestida de ludismo intrascendente) puede llevar, por ejemplo, a partir de "fricación" para hablar de un "amor que se africana" o hacerlo de un "pueblo [que] empieza con oclusión y oclusa con la velar" ( $T$, "Presentación del labio").

Los significados de los vocablos experimentan asl una trasformación sustancial que desvirtúa su contenido semántico para dar prioridad a lo que en la invención hay de ingenio y, por extensión, lo que en el español existe de potencialmente autogenerador. La traslación de significados es más chocante en un caso como el de "negrero", ninguna de cuyas dos definiciones tradicionales (dedicado a la trata de negros, o cruel con sus subordinados) es aplicable a esta frase: "¿Quién entrepone el gris, lo negrero, lo sucio?" ( $J$, II). Un posible caso de esa sinonimia de neologismos a que aludia antes se da poco después: "Sobre el negroso fin de Luzbel canta el coro".

Se trata, evidentemente, de realzar la expresividad, propósito al que coadyuva también la yuxtaposición en un solo bloque léxico de elementos linguisticos de progenie diversa a los que se convierte en configuradores de palabras inexistentes: "sinmigo" $(C, 5)$, "matepatemidad" ( $T$, "Presentación del labio"), "sonllorando" ( $T$, "Presentación del recuerdo"), "entrecomas" $(J, \mathrm{XI})$, "azulatria" (Test, "Antecedenta"), "ocrefrutal" (Test, "EJ pie"), "porentre" (Test, "Lo negro..."), "languidomundo" (Test, "Mi pluma"), "casquimanta" (Test, "Mi pluma"), "traslaponen" (Test, "Los anillos de plata"), "porentre / sinremedio" (Test, "La esperma"). lncluso es posible pensar en asociaciones no previstas por el autor: "concávidas" ( $J, V)$. Aunque es igualmente obligado suponer toda la intención en, por ejemplo, "cerrar los parpaduelos" ( $J$, XIV), o en "con prontitud y ciencia, con tundencia" ( $J, \mathrm{XI})$, donde, al eliminar la previsible sillaba con-del último sustantivo, se evita una quizá poco decorosa repetición 
("rundente" es adjetivo con el mismo significado que tiene "contundente"). Otro ejemplo curioso es "sinvivido" (Test, "Mi tos"): el sentido privativo de la preposición contrasta fuertemente con el caracter afirmativo de la palabra a la que se une. Este fenómeno de composición alcanza su máximo nivel de radicalismo en un verso de Turpa en el que el lector se tropieza con palabras yuxtapuestas y conectadas entre sí aparentemente solo por el capricho: "salmónenciclicatortura" ("Turpa crece...").

En un mundo literario con tan escasas concesiones al lector como las que realiza Ballesteros, filiar el origen de palabras desconocidas o descubrir el guiño a la historia de la literatura resulta ser una tarea realmente comprometida. No caracteriza al poeta su afición por los extranjerismos, aunque ocasionalmente se detecta una especie de retomo a los orígenes de la palabra que distancia a esta del español tanto como la aproxima a su procedencia: la voz de nuestro idioma que designa cierto arbusto importado por el francés Bougainville es, naturalmente, "buganvilla", pero en la poesia que analizo siempre aparece "bouganvilea(s)" $(J, \mathrm{IV} ; J, \mathrm{~V} ; J, \mathrm{XIV} ; N$, "Cinco"). Los galicismos crudos "regarda" (= mira; [Test, "Mi pluma"]) y "tomba" (= cae $[J, V ;$ Test, "Mi pluma"]) son, en este contexto tan favorable a la creación neológica como poco propicio a la voz foránea, anómalos; más, en cualquier caso, considerando el acentuado culturalismo de estos libros, que la recuperación del grecismo "potamós" ( $N$, "Nueve"), o el empleo de ese "cocle" ( $N$, "Cinco") que evoca el latín "cochlea" (= caracol), La misma lengua es fuente de "filia" (= hija $[J, 11]$ ), "génitos" (Test, "El pantalón..."), o "maretotum" (Test, "Lo que no fue..."). El hoy y el ayer del idioma se dan cita ocasional en la indistinción de la lengua poética de Ballesteros: "¿Qua non / la condición de conjugatio?" (Test, "El pantalón...").

El empleo de un forma verbal como "aduca" (Cova, "Sobre todo...") conjuga la idea de novedad en el uso y recuperación de una raiz lejana en el tiempo: hoy, "aducir", con la significación de "traer", es verbo anticuado. Otro ejemplo de retomo al pasado es "traervos" (Test, "Lo que no fue..."). El asimiento a siglos lejanos, si bien no iguala la importancia que alcanza el desarrollo del neologismo, no es objeto de olvido en estas páginas. Hasta nueve veces aparece en Jacinto el antiguo verbo "facer" en alguna de sus formas, y diez ocurrencias se registran, en el mismo libro, de "aqueste/-o/-as".

Por un lado, Ballesteros utiliza palabras aún incluidas en el léxico académico, pero con la etiqueta de "desusadas" o "anticuadas": "mutable" ( $T$, 
"Turpa crece más allá de todo"; $J$, VII) ?, "marfuza" (= engañosa $[T$, "En el atardecer..."; $J$, II]), "entrepone" $(J, 11)$, "mesquindaz" (sic; $J, 1 \mathrm{X})$; "asconde" $(J, \mathrm{IX})$; "rompida" $\left(J_{+} \mathrm{XI}\right)$, "seguranza" $(J, \mathrm{XII})$, "solitud" $(J, \mathrm{XIV})$, "animalia" (= animal [ $N$, "Nueve"]), "adamasquillo" (Test, repetidas veces), "densa" (= adensa [Test, "Mi cama"]), "estorcida" (= libertada de un peligro o aprieto [Test, "El pie"]), "cualque" (Test, "Lo que no fue..."), "esquividades" (Test, "La esperma"), "sinistra" (Test, "La esperma").

Por otro, presenta construcciones vigentes siglos ha y desechadas en la actualidad, pese a su supervivencia (en los casos del pronombre enclítico, y "so" en ciertas construcciones) en la lengua poética: "enla mi voluntad" (sic; $J$, IV), "hiciéronme" $(J, I X)$, "miranse" $(J, \mathrm{IX})$, "el su sitio" $(J, \mathrm{XI})$, "so" (preposición, en este caso precediendo al sintagma "los labios" [Test, "Mi cama"]), "dábasle" (Test, "Mi pluma"). Incluye, además, algún que otro vocablo ya olvidado por los diccionaristas del español actual: "requesta" ( $J, \mathrm{XI})$. La aparición, en lugares distintos de la obra de Ballesteros, de "mancebiello" ( $J$, XIV), "manciebillo/s" (Test, "Lo negro...", "Los anillos de plata" y "El pantalón...") y "mancebillo" (Test, "Mi pluma"), es quizá el ejemplo más relevante entre todos los que obligan a insistir en la dificultad de examinar palabras que posiblemente solo están en la mente de los responsables de las ediciones (en el último poema mencionado se lee, por cierto, "donceliello").

El sintagma "del burral a la gloria" (Test, "El pie") ejemplifica dos fórmulas distintas de subversión lingulstica. El adjetivo es hoy poco o nada usado, pero además se ha producido ahí uno de esos cambios de categorla gramatical tan frecuentes en estos libros. El adjetivo se convierte en inesperado sustantivo ("un cúmulo de falsas" [ $J, \mathrm{X} 1$ ]; "la inmensa selvática" [Test, "Mi cama"]), o a la inversa ("cosa huesa y blanda" [ $T$, "Presentación de la mano"]; "aire collarino" [Test, "Los anillos de plata"]). Más sorpresivo resulta ver convertido un sustantivo en sl mismo infrecuente, como lo es "sonriso" (= sonrisa) en adjetivo, como hace el escritor en Jacinto (IV) ${ }^{8}$. El ejemplo de "página anversa" $(J, I V)$, que ilustra la opción sustantivo $\rightarrow->$ adjetivo, es analógico con "reversa", que se usa en el sigujente verso y que, a diferencia de su antónimo, sl tiene reconocida por el diccionario académico su condición de posible adjetivo.

7 Hay una curiosa contradicción, relacionada con esta palabta, entre los diccionarios académicos. "Mutable" es arcajsmo en las ediciones del usual, pero no en la última del Manual, precisamente caracterizado por prescindir de los vocablos en desuso

"Otra curiosidad de los diccionarios académicos: mientras que la palabra "soniso" es desusada para el Manual, tal adjetivo no existe en el usual 
En secuencias como "cosa pulpa" ( $N$, "Cinco"), "la numeraria" ( $N$, "Seis") o "arbustas jaras" (Test, "El pantalón...") hallamos otros casos de subversión doble: cambio de categoria gramatical, pero también de género. Este segundo recurso es, desde el punto de vista cuantitativo, uno de los predilectos del autor $\mathrm{y}$, amén de uno de los que más contribuyen al distanciamiento del lector, sin duda extrañado y hasta perplejo por el hecho de que, sin más razón aparente en muchos momentos que el simple propósito (suficiente, si se quiere) de romper con las normas tradicionales, se modifique el género de los sustantivos.

Los mecanismos son dos: simple cambio de artículo y variación morfológica en el sustantivo, complementando dicha trasformación. El segundo implica un grado mayor de subversión: "cimbrios" (cimbra = amazón que sostiene un arco [ $J, \mathrm{VII}])$, "zozobro" $(J, I X)$, "parameros" $(J, X)$, "peluso" $(J$, $\mathrm{XIV})$, "finalia" ( $J, \mathrm{XIV})$, "prodigia" $(J, \mathrm{XV})$, "arquitraba" $(J, \mathrm{XV})$, númera $(N$, "Cuatro"), "marasmas" (Test, "Antecedenta" y "Lo que nunca"), "testigas" (Test, "El pie" y "Mi pluma"), "alcoras" (Test, "Lo que no fue..."), "dúctila" (Test, "Lo negro..."), "solazas" (Test, "Lo negro..."), "collara" (Test, "Mi pluma"), "berébar" (por "beréber" [Test, "Los anillos de plata"]), "populara" (Test, "Los anillos de plata"), silencia (Test, "Los anillos de plata"), "ángela" (Test, "Mi tos"), "bủha" (Test, "El pantalón..."), y, naturalmente, "testamenta" (título del último libro, que contiene otros ejemplos de uso de esta voz).

El primero de los dos recursos enumerados es, sin embargo, más ajeno a la sensibilidad del lector ": "el nada" $(C, 10)$, "la si" $(C, 12 ; J, X 1)$, "un comezón" ( $T$, "Presentación del sexo"), "las estigmas" $(J, V)$, "la drama" ( $J$, VIII), "el pleamar" ( $J$, IX), "el máquina" $(J, \mathrm{IX})$, "la sol" $(J, \mathrm{X})$, "la Alá" $(J$, $\mathrm{XI})$, "la do" ( $J, \mathrm{XII})$, "el encimera" ( $N$, "Uno") ${ }^{10}$, "el desazón" ( $N$, "Uno"), "el espuma" ( $N$, "Uno"), "la tiemblo" (= temblor; $N$, "Siete"), "al luz" ( $N$, "Nueve"), "la chapitel" (Test, "Lo que no fue..."), "la hombre" (Test, "Lo que no fue..."), "la Dios" (Test, "Los anillos de plata"), "la solaz" (Test, "La esperma"), "la mantel" (Test, "La esperma"). A un cierto efecto cómico parece aspirar la invención de la imposible voz de tenora $(J, \mathrm{XII})$, y un caso curioso es la aparición de un femenino, "los austriacas" ( $T$, "EI huevo se hizo sombra"), que hay que imaginar procedente de la confluencia de austriacos y "los Austrias".

${ }^{9}$ Rosa Romojaro $(1987,128)$ escribe que "el principio motor del sistema creativo" de Turpa es "la fusión de núcleos nominales o verbales a modificadores o complementos no pertinentes en cuanto al sentido lógico".

${ }^{10}$ Una última nota sobre lexicografía académica: la palabra no está recogida en los diccionarios de la corporación con el significado bien conocido por las amas de casa. 
El empleo de "lo" en circunstancias gramaticalmente anómalas había asomado en La cava ("lo cimiento" ["Zoón-Politikón"]), pero se reafirma, tras un largo paréntesis, en Testamenta: "lo sin miedo" ("Antecedenta"), "lo sl" ("Antecedenta"), "lo todo" ("Mi cama"), "lo cuévano" (Test, "Lo que nunca dije"), "lo dolo" ("Los anillos de plata"). El propósito distorsionador de la convención es claro en esta doble trasgresión: "el mujer: la hombre" (Test, "Mi tos"). En el mismo poema encontramos, sintetizando el sintagma "tigre de Bengala", un mismo sustantivo con dos géneros distintos: "bengala" y "bengalo".

Acción contra la norma es también elegir el artículo femenino precediendo a $a$-: "la agua" (Cava, "Sobre todo..."), "la alba" (Cava, "Sobre todo..."; $J$, XIV), "la ave" ( $J$, I y II; $N$, "Dos"), "la haz" (Test, "Lo que nunca dije"). Como en otros casos, también en este punto es posible señalar la presencia de dobletes: "la torrente" en La cava ("Zoón-Politikón"), pero "la torrenta" en Jacinto (XIII).

El tratamiento de este tema por parte del autor es a todas luces consciente. La vacilación de género queda registrada, a manera de principio poético, en un sintagma en que el sustantivo parece dudar sobre sus atributos sexuales: "aquel aquella fina agua" ( $T$, "Presentación del recuerdo"). $O$ en aquel verso donde los dos nombres intercambian sus artículos normativos: "La beso. Los caricias" (Cava, "La cava") ". Aunque tal vez la ruptura más brusca ante los ojos del lector sea la propiciada por una combinación tan compleja como la formada por un calificativo masculino, un determinante femenino y el sustantivo al que acompañan, indeciso, por sus propias características, entre uno y otro: "¿Qué hermoso esa color!" ( $N$, "Nueve").

Frente a estas mutaciones genéricas, los experimentos linguísticos con el número son menos numerosos: "las cales" ( $J$, IV y VIII), "los julios" ( $J$, IV), "los más allás" ( $N$, "Cuatro"), "las nadas" (Test, "Antecedenta"), "los dentros" (Test, "Antecedenta" y "La esperma"), "los envés" (Test, "Mi pluma").

Ballesteros retuerce el lenguaje, lo fuerza para provocar ese extrañamiento de un lector posiblemente ya lejano. $Y$ si los sustantivos admiten articulos imprevistos, los verbos aceptan un régimen que no les es propio: "perdura" como transitivo $(J, \mathrm{Il})$, "persevera" como reflexivo $(J, \mathrm{~V} 1 \mathrm{l})$ o

11 Fue precisamente este verso el que dio pie a José de la Calle $(1985,40)$ para formularse estas pregunta sobre la intención de Ballesteros: "¿Qué pretende el poeta corrigjendo a la gramática, herrándola, errando y tergiversando los géneros? ¿Nos sugiere con ello, tal vez, que sería más lógico -mís acorde con cierta lógica-s, que 'beso' fuese femenino y 'caricia' masculino? Allá el lector". El comentario, inserto en un texto a proposito del concepto de errata, partía de la audición de una lectura de poemas del escritor andaluz, a cargo del propio autor. 
"adulterar" (= cometer adulterio) como "transitivo" (Test, "El pie"). Cuando el poeta escribe "el pan tierno se langui-/decia" $(C, 26)$, utiliza este recurso de retorsión del verbo, más otro nada infrecuente en sus páginas: la sección de una palabra a final de verso. Se prodigan los ejemplos de esto último en Contracifras, pero no, curiosamente, en los libros posteriores: en el primero, "Nitaria-/mente-sa" (6), "corona-/do" y "a-/tención" (7), "do-/blado" (8), "tro/pel" (11), "doble-/mente" (19), "meticulo-/samente" (24), "cato-/lizaba" (26), pero en Jacinto solo "des-/pareciendo" (IX). Con menor frecuencia se registra esta misma ruptura dentro de una palabra integrada en un único verso: "fal-so" $(C, 28)$, "hipo-potamós" ( $N$, "Nueve"). Es ocasional la inserción de una sílaba perturbadora: "albari-tu-coque" ( $N$, "Ocho").

$Y$ aunque no sea tampoco uso constante la elisión de silabas ("muer-" $[C, 22])$, sí lo es la de palabras o frases enteras al final de un grupo de versos, con lo que el pensamiento queda incompleto y el lector, una vez más, perplejo: "Y sufro $y "(C, 4)$, "se refería a" $(C, 5)$, "Asi que" $(C, 18)$, "la tierra que" $(C$, 22), "todos sepáis que" $(J, I)$, "Sabed bien que" $(J, 1)$, "cómo no" $(J, 1)$, "E1 calor, el englobe, la..." ( $J, \mathrm{XII})$, "mirando sus!" ( $N$, "Cinco"), "sin tino, sin" (Test, "Mi pluma"), "Tú siempre la" (Test, "Mi tos"), "siendo tủ la" (Test, "Mi tos").

La lengua canónica es objeto, como se ha podido advertir, de todo tipo de manipulaciones en la producción de Ballesteros, hermética por su contenido, pero también por su presentación verbal. Los pronombres se trasforman: "en tú" (Cava, "La cava"), "sobre tú mismo" (Test, "Mi cama"), "entre tú" (Test, "Mi cama"). La ordenación lógica de los elementos sintácticos cae abatida ante el acoso del creador: "Tú imagina y lo piensa" $(J, \mathrm{Xl})$. El orden $y$ el concierto parecen haber dejado campo libre a combinaciones imposibles: "un tras lo todo" (Test, "Mi los"), "no la todo es" (Test, "El pantalón..."). Las palabras parecen rebelarse y reclamar un sitjo distinto de aquel que la tradición no respetada por el poeta parece haberles asignado: "a mira de punto" $(C, 16)$. Pareceria que exigen duplicar su existencia: "para la ver la vida" $(C, 2)$, "Todo lo Dios lo sabe" $(J, \mathrm{Vl})$. O forzar la presencia de un apoyo presentáneo para hacer valer su existencia como tales vocablos: "la Ella" $(J$, repetidas veces), "aquella la luz" ( $J, I V)$, "en ahora" $(J, \mathrm{Vl})$, "el aquello" ( $J$, VIII), "las aquellas" ( $J$, VIII), "del aquel centurión" (Test, "El pie").

La abundancia de ejemplos obliga a dar por supuesta la existencia de un programa de socavación de las bases del edificio linguistico normativo, al mismo tiempo tal vez que del propio proceso de comunicación entre el texto y un lector necesariamente distanciado. Se dirla que esta voz de la subversión reclama a gritos su sitio a medio camino de la tradición literaria y el experimentalismo más radical y destructivo. En tal punto intermedio podria quizá 
localizarse esta obra cerrada (por dificilmente accesible) que hunde sus raíces más profundas (que no las más consistentes, ni tampoco las más visibles) en la vanguardia de entreguerras a la que alude el lema de la poesla 16 de Contracifras: "Neo-dada-susu-rerre-siempre". Es esta la composición que sigue en el orden a la única de Ballesteros carente casi por completo de puntuación. Curiosamente, casi nunca se atenta contra esta en los libros analizados. Quizá porque representa el punto de equilibrio entre aquella tradición y esa vanguardia que se unen (tensa unión, preludio quizá de una separación no amistosa) en unos versos repletos de claves, muchas de ellas indescifrables.

\section{OBRAS CITADAS}

BALLESTEROS, Rafael. 1995. Poesia completa (1969-1989). Mảlaga: Ayuntamiento.

--.. 1992. Testamenta. Madrid: Visor.

CALLE, José de la. 1985. "El placer de lo oculto (o culto placer). Ruido de erratas", Puertaoscura (Málaga), n. 1.

ROMOJARO, Rosa. 1987. "Una poética manierista en los años setenta: Turpa de Rafael Ballesteros", Analecta Malacitana, 10 